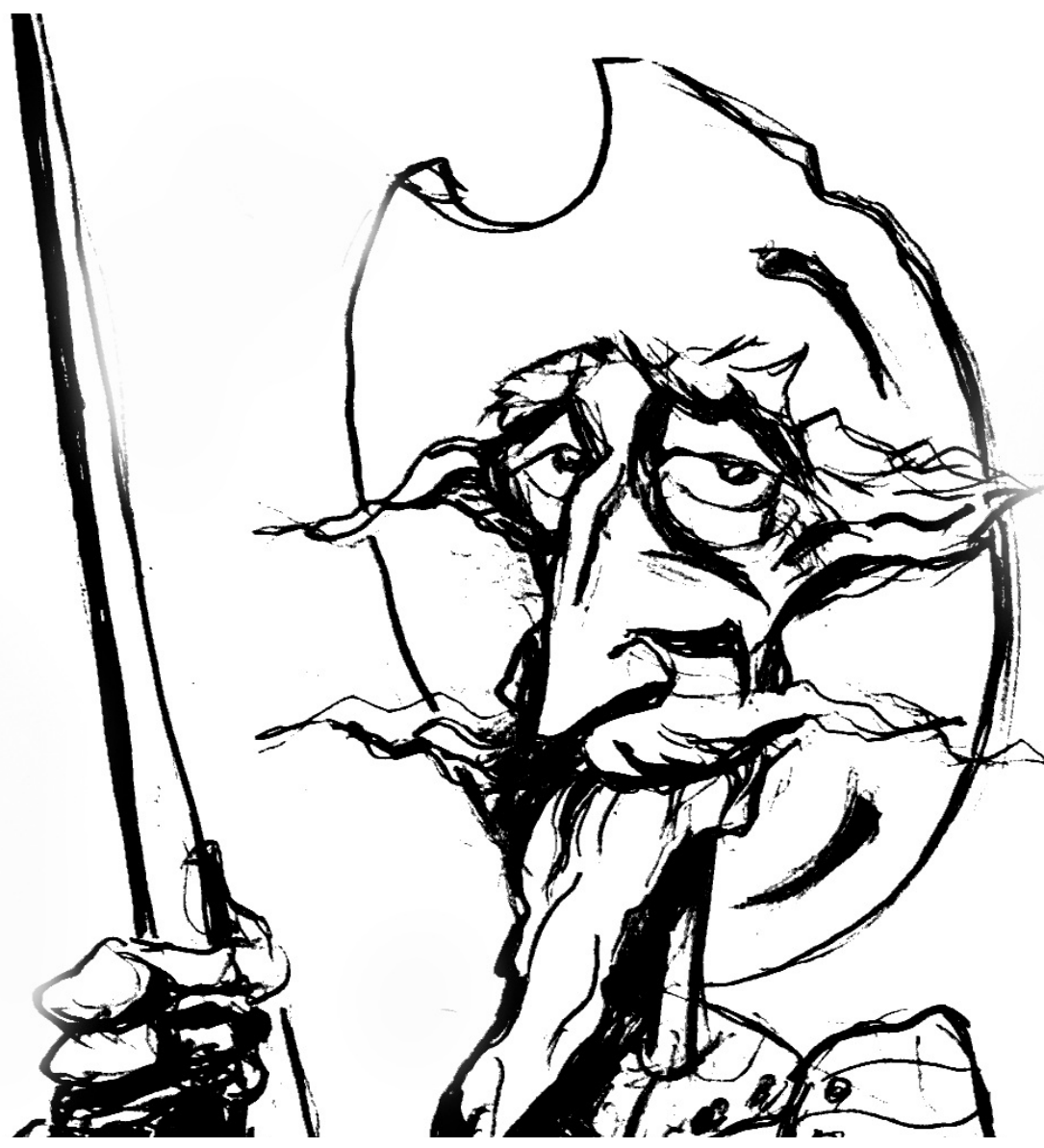

1874: El Ejército nacional frente al dilema mitrista.

La disputa entre las lealtades políticas y la subordinación al Estado

[Lucas Codesido] 



\title{
1874: El Ejército nacional frente al dilema mitrista. La disputa entre las lealtades políticas y la subordinación al Estado*
}

\author{
1874: The National Army Faces the Mitrista Dilemma. The Dispute between \\ Political Loyalties and the Subordination to the State
}

LUCAS CODESIDO

\section{Resumen}

En este trabajo se examinan los componentes de las fuerzas enfrentadas a partir de septiembre de 1874 con motivo de la rebelión mitrista. Se estudia la trayectoria profesional de los oficiales involucrados y el papel desempeñado por las lealtades políticas y los vínculos personales a la hora de ser incorporados en alguno de los bandos en contraste con un arquetipo de sujeción propio de la institución militar concebida como brazo armado del Estado nacional. También se propone esclarecer los mecanismos utilizados por ambas formas de organización militar para conseguir recursos humanos y apoyo material. Por último, se presentan algunas derivaciones de los sucesos de 1874 en la arquitectura del Ejército Nacional.

\section{Palabras clave}

Fuerzas armadas; Siglo XIX; Ejército Argentino;

\begin{abstract}
This work examines the components of the forces confronted from September 1874 onwards during the mitrista rebellion. The professional career of the officers involved, and the role played by political loyalties and personal ties in being incorporated into one of the camps is studied in contrast with an archetype of subjection typical of the military institution conceived as the armed wing of the national State. It also aims to clarify the mechanisms used by both forms of military organization to obtain human resources and material support. Finally, some derivations of the events of 1874 in the architecture of the National Army are exposed.

\section{Key Words}

Armed Forces; Nineteenth Century; Argentine Army; State-Formation; Mitrista Rebellion
\end{abstract} Estado nacional; Rebelión mitrista

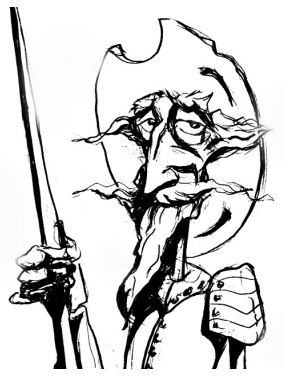

Recibido con pedido de publicación el 20 de agosto de 2020

Aceptado para su publicación el 31 de octubre de 2020

Versión definitiva recibida el 15 de diciembre de 2020

Lucas Codesido, Universidad Nacional de La Matanza, La Matanza, Argentina; e-mail: lcodesid@ungs.edu.ar

* Agradezco las recomendaciones y sugerencias de los evaluadores anónimos de la revista

Esta obra se publica bajo licencia Creative Commons. Atribución-NoComercial-CompartirIgual 4.0 Internacional

Codesido, Lucas "1874: El Ejército nacional frente al dilema mitrista. La disputa entre las lealtades políticas y la subordinación al Estado", Prohistoria, Año XXIV, núm. 35, jun. 2021, pp. 29 - 54 


\section{Introducción}

La militarización de la vida política argentina que caracteriza a este período nos brinda el marco más general donde sucede la contienda de 1874. Como ha señalado Oscar Oszlak, la conformación del Estado implicó un proceso de "expropiación social" en el cual la entidad nacional incipiente se fue apropiando de un conjunto de atribuciones y ámbitos de actuación que eran propios de otras instituciones de la sociedad. En los últimos años, este enfoque ha sido enriquecido a partir de la investigación empírica sobre los distintos ámbitos provinciales. Se ha propuesto que las normas, las prácticas y acciones políticas orientadas a conducir la autoridad hacia el poder central no surgen de una estricta penetración del Estado nacional sobre la sociedad sino más bien, de una interrelación entre los poderes provinciales y los nacionales ${ }^{1}$. El Estado nacional será una forma de organización política que se edifica sobre otras formas de autoridad preexistentes, de modo que se deben examinar los ritmos y particularidades que su trayectoria asume en las diversas realidades provinciales. En este trabajo nos interesa vincular al fenómeno de la guerra con el proceso de construcción del Estado nacional a partir de la crisis política devenida en enfrentamiento armado. Nos interesa indagar en torno del papel de la guerra y sus derivaciones en la reestructuración y los cambios operados en una organización militar que se proyecta como brazo armado del Estado en formación (Garavaglia, 2012: 413-456). ${ }^{2}$ Este conflicto nos ofrece un sitio de observación para realizar un examen de la organización militar a través de los componentes de ambas fuerzas enfrentadas. Repasar los marcos de experiencia común que reúne la historia militar de los oficiales participantes y que a su vez forjaban la carrera militar de cada uno, nos permitirá plantear algunas consideraciones a tener en cuenta a la hora de referir las motivaciones que llevaron a unos y otros hacia la identificación y participación en los bandos enfrentados. Para ello vamos a indagar en torno del grado de autonomía con

\footnotetext{
${ }^{1}$ El estudio colectivo compilado por Bragoni y Míguez (2010) da cuenta del trabajo de historiadores atentos a las diversas realidades provinciales sobre las que se edificaría el Estado nacional. El análisis empírico de los factores que impulsaron la integración nacional y su impacto sobre la dinámica del funcionamiento de la sociedad provincial, junto con el análisis de las estrategias desplegadas por las elites locales para conducir sus intereses dentro de las instituciones nacionales, permite vislumbrar las peculiaridades que asumió el poder disruptivo del Estado nacional en cada uno de aquellos espacios provinciales.

${ }^{2}$ El objetivo general sobre el que se proyecta esta investigación es contribuir al conocimiento del proceso de construcción del Estado nacional, desde el estudio de la renovación y modernización del Ejército. Una perspectiva que propone trazar la trayectoria de los actores e instituciones que han concurrido desde el plano militar a transformar la dinámica de las relaciones entre el Estado nacional, las provincias y otros agentes de la sociedad argentina. El objeto de análisis propuesto se liga en la continuidad de nuestra investigación de tesis doctoral: "Armar al Estado, construir la Nación. La nacionalización de las fuerzas armadas en la Argentina y su vinculación con el proceso de construcción del Estado (1862- 1880). FaHCE/UNLP (2016).
} 
que contaban los oficiales del Ejército a la hora de actuar militarmente. Por un lado, revisaremos el papel de las afinidades políticas y las lealtades personales de tipo clientelar, y por otro, la importancia otorgada a la disciplina y al sentido del deber en una institución que sitúa a sus miembros a modo de eslabón en una cadena de mandos que se erige como brazo armado del Estado nacional. Más adelante examinamos los diversos mecanismos puestos a conseguir recursos humanos para la tropa, por parte de ambos bandos, reseñando las irregularidades que surgen durante esas movilizaciones y los resultados obtenidos en función de las posibilidades de acción que permiten las prácticas formales e informales de reclutamiento. Finalmente señalamos algunas derivaciones que la derrota militar del mitrismo promovió o permitió cristalizar en la arquitectura del Ejército Nacional.

\section{El "último recurso", la revolución}

\author{
Ahí jué lo güeno... Ah picaso, \\ Montaron ya los mitreros, \\ Comenzando sus diareros \\ A asegurar que pa el caso, \\ No valía esa eleición, \\ Que Don Mitre presidente, \\ Había é ser contra el torrente, \\ Que habría Rigolución!
}

\author{
Que la tropa é linia tuita \\ Con Don Mitre se iba á alzar, \\ Agatas pa comenzar! \\ Y que el día de la cita, \\ Todos los gefes mentaos \\ Con sus milicos vendrían \\ $Y$ al gobierno azonzarian \\ Como manga é condenaos ${ }^{3}$
}

El diario La Nación de Bartolomé Mitre se refería a la alianza entre Nicolás Avellaneda y Adolfo Alsina, como a esa "rara mezcla entre porteños extremistas y sus aliados federales" (Serrano, 1995:19) a la que atribuía la maquinación de unas elecciones amañadas e ilegítimas. La tarea de los mitristas a partir del resultado electoral adverso se orientó a comprometer a las unidades de línea comandadas por simpatizantes de la causa y a movilizar a los pobladores de las provincias de Buenos Aires, Córdoba y Santa Fe. A partir de los resultados en los comicios para diputados de febrero de 1874, marcados por la derrota del Partido Nacionalista (mitrista) y las protestas por un presunto fraude electoral, se había formado un comité de miembros de esa fuerza. En sus reuniones comienza a plantearse el tema de la revolución: “cuando se veían

\footnotetext{
${ }^{3}$ D. A., Recuerdos de la revolución del 24 de septiembre de 1874, Relación de los paisanos Maldonao y Contreras, Imprenta "Del Mercurio", diciembre de 1874. Del autor solo aparecen sus iniciales, D. A. Es un relato en forma de poesía gauchesca que contiene una visión muy negativa sobre el alzamiento mitrista. Describe el encuentro entre dos paisanos amigos, donde Contreras le relata a Maldonado la amarga experiencia que tuvo al verse involucrado con los revolucionarios, por haber sido víctima de las mentiras de Mitre y sus seguidores.
} 
puestos en práctica todos los resortes de la inmoralidad y el vicio, el único camino que se presentaba a los ciudadanos honrados [...] era el de la revolución", comentaba uno de sus miembros, Florencio Del Mármol (Del Mármol, 1876: 9). A partir del 11 de julio, cuando la Cámara de Diputados expidió la aceptación del resultado de las elecciones de febrero, el grupo de mitristas pasó a denominarse Comité Revolucionario. ${ }^{4}$ Se anunciaba en una proclama que "ha llegado el momento que el Partido Nacionalista se ponga en pié y acepte la lucha en el terreno de la fuerza a que le han arrastrado sus opresores...". ${ }^{5}$ José C. Paz, editor del diario La Prensa anunciará la revolución ${ }^{6}$ el mismo 24 de septiembre en un editorial titulado "Último recurso", donde plantea que ha llegado la hora de tomar las armas en nombre de "la sociedad, la Constitución y las leyes del pueblo argentino". ${ }^{7}$ La prensa escrita jugaría un importante rol durante la campaña militar. Los diarios operarían como boletines de campaña, donde se daban a conocer las distintas proclamas y sus correspondientes réplicas por parte de ambos bandos. La función primordial que les cupo fue la ofensiva de propaganda o "guerra psicológica" para desgastar al adversario, en la que triunfaron desde un comienzo los periódicos afines al gobierno, desacreditando la legitimidad del levantamiento revolucionario. ${ }^{8}$ Una vez que se hizo pública la incorporación de las fuerzas indígenas de Cipriano Catriel a la rebelión, las proclamas de Mitre fueron reformuladas en forma de parodia por los diarios afines al gobierno nacional con editoriales que se mofaban por el escaso contenido de civilización de un movimiento que da cabida a 1500 indios salvajes y dice luchar por las libertades constitucionales. ${ }^{9}$ Una prensa que no vacila en calificar de montoneras (Míguez,

\footnotetext{
${ }^{4}$ En abril habían sido los comicios de electores a presidente. El 6 de agosto se realizó el escrutinio que definió a la fórmula presidencial ganadora: Nicolás Avellaneda-Mariano Acosta: 146 electores, y Bartolomé Mitre-Juan Torrent: 79. El resultado no convenció al mitrismo que radicalizó sus ataques, a partir de una campaña periodística en la que se incitaba abiertamente a impedir que el 12 de octubre el presidente electo asumiera sus funciones.

${ }^{5}$ Proclama del General Mitre (Del Mármol. 1876: 147-150).

${ }^{6}$ Sobre el concepto de revolución en este contexto ver: Míguez (2011: 180-205) y Sabato (2009: 159-182).

7 “Dispuestos siempre al sacrificio en defensa del pueblo y de sus instituciones nuestra opción ya está hecha [...] cerramos desde hoy la sección editorial de La Prensa para ponernos al servicio del pueblo en el terreno de los hechos". Editorial de La prensa, 24 de septiembre de 1874.

8 "¿Acaso puede llamarse reivindicación de derechos lo que el General Mitre busca, cuando no busca otra cosa que la posesión del poder? ¿Acaso lucha por la civilización cuando se une á los indios de la Pampa y busca su apoyo para venir á imponer su personalidad probada ya hasta el cansancio, vieja, debilitada, gastada y rechazada por la palabra inapelable de las urnas? No: no puede ser. El General Mitre en campaña no tiene un propósito elevado y digno. Esa campaña abierta con el robo de una cañonera, el asesinato de un Coronel de la República, y la traición de dos jefes extranjeros al servicio de la Nación, es obra de bandidos". La Tribuna del 17 de octubre de 1874 (Saldías, 1988 [1910]: 120-121).

${ }^{9}$ El diario La República publicaría la "Segunda proclama del tercer abono, BARTOLON ME MITRE. Dios de los robos y los proveedores, Á los argentinos que aspiren a la ridiculez de su patria. Com...padritos- Llamado por Catriel y los indios de su tribu que protestan con las
} 
2011) a las fuerzas insurrectas y que expresa la guerra de las opiniones como herramienta para debilitar al enemigo. ${ }^{10}$

El propósito central de la insurrección era impedir la asunción presidencial de Nicolás Avellaneda, acto programado para el 12 de octubre de 1874. El Comité Revolucionario había diseñado una estrategia basada en el avance de fuerzas militares desde los cuatro puntos cardinales sobre la ciudad de Buenos Aires. La maniobra había sido concebida como un golpe cuyo éxito dependía del elemento sorpresa y la rapidez de su ejecución, con un movimiento que debía concentrar toda la acción sobre el espacio de la ciudad de Buenos Aires, donde ocurriría la asunción presidencial. Estas singularidades, sumadas a la confianza depositada en las fuerzas de línea para ejecutar la parte más importante de la operación, daban a la operación militar el carácter de un putsch, antes que el de un levantamiento popular.

\section{Ciudadanos armados o veteranos de línea: los soldados de la revolución según el comité revolucionario}

Una vez que el Comité Revolucionario se decidió por el recurso de la acción armada, la atención del grupo se dirigió a preparar los elementos que deberían dar forma a las fuerzas revolucionarias. Las discusiones acerca de la configuración de las fuerzas militares tenían como eje del debate el problema de precisar sobre quienes debería recaer el mayor peso y responsabilidad de las operaciones. Las opciones eran dos: Ejército de Línea o milicias. La primera estaba representada por los jefes de las veteranas fuerzas de línea que habían confirmado su participación junto con las fuerzas que respondían a su mando. La segunda vía discutida fue la formación de milicias populares basadas en el principio de la ciudadanía armada (Sabato, 2009; Macías, 2016) que serían

chuzas en la mano porque no se deja en mi poder el dinero de la aduana, para enriquecer a los que me regalan vinos y tabaco cuyo valor conocéis [...] me pongo en campaña al frente de un ejército de vándalos que combate porque Catriel sea catedrático de derecho constitucional en la Universidad de Buenos Aires, Agustín García de baile y Eduardo Costa de cálculo diferencial entre deudores y acreedores, y asumo la responsabilidad de todos los robos que se cometan". Diario La República 3 de noviembre de 1874, en Archivo General de la Nación (AGN), Sala VII, Documento 1038 (Donación J. J. Biedma). “Un periodista extranjero retrataba al Cacique Catriel con frac, sombrero de copa y guante blanco, y vestidos de indios, que le seguían, á los Generales Mitre, Gelly y Obes, Arredondo y Rivas, Doctores Costa, Rawson, García, Muñiz, los Elizalde, Lastra, Terry, Quirno Costa, etc., y ponía en boca del cacique estas palabras: ¡Qué vergüenza! Un hombre decente como yo conducido por esta indiada." (Saldías, 1988 [1910]: 121).

${ }^{10}$ Las consideraciones sobre los indígenas varían si estos dan su apoyo al bando propio. Cuando el coronel Julio Campos consigue que los indios de Catriel se pasen a sus filas, dirá que ahora "se han alistado en las filas del Gobierno, no como soldados de la licencia y del pillaje, sino como soldados del orden y las instituciones". Boletín del Ejército del Sud, 20 de noviembre de 1874. En AGN, Sala VII, Archivo del señor J. Biedma, Documento 1038, sin paginación. 
costeadas por las donaciones acercadas al Comité a través de la ayuda de algunos notables adictos a la causa. La opinión de Mitre fue el factor determinante que inclinaría la balanza hacia la primera opción, cuando este afirmara que "el concurso único de las fuerzas de línea había de dar cuenta satisfactoria para la causa de la revolución" (Del Mármol, 1876: 11-13). A partir de la postura de Mitre cuenta Del Mármol que "la inversión que se dio a este dinero, estuvo en un todo consecuente con el plan à que la mayoría del Comité se proponía ajustar el pronunciamiento de los sucesos. En vez de emplearlo en proporcionarse el armamento propuesto, se distribuyó entre varios jefes del ejército de línea, para que atendieran á todas las necesidades que fuera menester vencer" (Del Mármol, 1876: 14).

Los generales José Arredondo e Ignacio Rivas, y el Coronel Francisco Borges ofrecieron su participación, y contaban con la preferencia del comité debido al prestigio que rodeaba a estas figuras por su larga trayectoria de servicios militares, antes y durante el gobierno de Mitre. De todos modos, hubo cuerpos conducidos por civiles, aunque admitidos desde un rol complementario de las fuerzas regulares sobre las que se había depositado la parte principal de las operaciones. También se discutió y aprobó la posibilidad de armar a estas milicias en el seno de aquellos encuentros, aunque las conclusiones giraron en torno de la idea de que el éxito militar estaría representado por el concurso de las veteranas fuerzas de línea. Esa convicción fue reforzada por Mitre quien basaba su argumentación en la influencia de los jefes militares sobre sus subalternos y otros jefes que se sumarían a la causa una vez producido el movimiento, en una especie de efecto dominó. Mitre era consciente de que la disciplina y experiencia adquirida por las fuerzas de Línea en la Guerra del Paraguay y las batallas contra los jordanistas sería difícilmente neutralizada por un ejército compuesto de civiles sin instrucción militar. ${ }^{11}$

La confianza depositada en esos jefes militares, antiguos subalternos de Mitre, otorgó un protagonismo mayor del que se esperaba en jefes como Rivas y Arredondo, encargados de concurrir con las fuerzas reclutadas en las áreas donde desplegaban su influencia como jefes de frontera. Allí se concentraban las tropas de Línea al servicio del gobierno, complementadas con la Guardia Nacional de los distritos cercanos, más las tribus de indios amigos y otros individuos cercanos a los jefes militares ${ }^{12}$. La dinámica propia de las relaciones políticas en la frontera bonaerense permitió la incorporación de Cipriano Catriel al frente de 1500 indios a las columnas de Rivas para combatir en las filas del Ejército Constitucional. Sin embargo, la concurrencia de las fuerzas indígenas resultaría ineficaz en términos militares, y sería políticamente muy costosa para la figura de Mitre.

\footnotetext{
${ }^{11}$ Mitre proponía el recurso del Ejército argumentando que de esta manera el país se ahorraría "el derramamiento de la sangre del pueblo" (Del Mármol, 1876: 13-14).

${ }^{12}$ La dinámica de esas relaciones en Míguez (2010 y 2011).
} 
Los mitristas esperaban la adhesión de Santiago del Estero, su clásico aliado en el interior, pero los Taboada, aunque en un primer momento adhirieron a las proclamas y reafirmaron su lealtad personal a Bartolomé Mitre, permanecieron imparciales en su provincia. Corrientes, la otra provincia con fuerte influencia del Partido Nacionalista tampoco tuvo la reacción que se esperaba, solo la ciudad de Goya fue dominada a fines de octubre por un grupo comandado por el Coronel Plácido Martínez, resistencia que se disolvió a principios de diciembre sin comprometer grandes recursos militares nacionales. Transcurridas unas semanas desde el comienzo de la revolución, que esperaba obtener el concurso y adhesión de todas las fuerzas "constitucionales" del país, el alzamiento quedaba circunscripto a una parte de Cuyo y al sur de la provincia de Buenos Aires. El avance de Arredondo por la región de Cuyo y particularmente en San Luis y Mendoza muestra algunas de las características que adquirió el proceso de movilización que iría a sostener a las fuerzas revolucionarias. Varios personajes identificados con el poder local negociaron su participación en alguno de los bandos intentando resguardar y conservar sus posiciones de influencia (Bragoni, 2010: 34-38). El contexto mendocino se hallaba convulsionado desde 1873 luego de la elección para gobernador que dio por ganador a Francisco Civit, cuando después de conocido el resultado de aquella, el coronel de la nación Ignacio Segovia se sublevó contra el nuevo gobierno recibiendo el apoyo de los derrotados "gonzalistas", adherentes a la candidatura de Carlos González Pintos. La elección provincial había estado atravesada además por la puja nacional que definiría la cuestión presidencial, los civitistas propiciaban la opción por el partido oficialista que conduciría a la candidatura de Avellaneda, y los gonzalistas eran fervientes partidarios del mitrismo. Cuando se produjo ese levantamiento de 1873 Sarmiento declaró el estado de sitio en la provincia y envió a Teófilo Ivanowski a reprimir a los insurrectos quien por un golpe de mano y sin mediar batalla de por medio provocó la rendición de los rebeldes. ${ }^{13}$

\footnotetext{
${ }^{13}$ Otras razones que explican el apoyo dado a la revolución en Mendoza se vinculan con las medidas del gobierno de Civit tendientes a la concentración de la administración y los cargos públicos. La llegada de Arredondo a la provincia y su triunfo en Santa Rosa el 29 de octubre de 1874 produjo el derrocamiento de Civit. Fue reemplazado por un gobierno de los llamados gonzalistas que pronto se alineó con las consignas del levantamiento mitrista en la "lucha contra los gobiernos electores" y la "defensa de las libertades perdidas". Sergio Daghero (2014) reconstruye la trayectoria de la revolución de 1874 en el espacio cuyano y cordobés. Examina la configuración de las facciones intervinientes. Aparecen personajes como Mario Frigolé, quien dirigió la resistencia del gobierno legal en Luján de Cuyo y luego desertó para sumarse a las filas de Arredondo. Ambrosio Videla, teniente del gobierno legal se cambió de bando luego de haber sido ascendido a capitán por los revolucionarios. Otro teniente de las fuerzas del gobierno legal que luchó en Santa Rosa luego pasó a instruir a la Guardia Nacional en el bando rebelde. El sargento Tomás Maldonado se pasó a las filas rebeldes entregando además a los soldados de su compañía, y hay más ejemplos (Daghero, 2014: 58).
} 
La provincia de Jujuy fue otro de los lugares en los que se produjo un movimiento revolucionario en el cual las demandas de los insurrectos eran a la vez expresión de conflictos locales que pronto se vincularían al escenario nacional. En la puna jujeña el poder revolucionario se expresó en una violenta rebelión de campesinos armados a partir de un conflicto por la posesión de la tierra que se combinó con los sucesos de la política nacional (Paz, 2010: 423442). ${ }^{14}$ En enero de 1875 el movimiento fue derrotado por la intervención del gobierno nacional, que movilizó a la Guardia Nacional de Salta para reforzar a las fuerzas del gobernador Álvarez Prado, dando por concluida oficialmente la revolución mitrista. ${ }^{15}$

\section{Perfil y trayectoria de los oficiales leales y rebeldes}

Los combates del año 74 movilizaron a miles de hombres en cada uno de los bandos enfrentados. Casi todos los oficiales que participaron en el conflicto habían combatido en la campaña del Paraguay, en las rebeliones federales de fines de la década del sesenta y en la guerra contra el jordanismo. Esta experiencia común que reunía la historia militar de todos los participantes y que a la vez forjaba la carrera militar de cada uno por separado, nos plantea algunas consideraciones a tener en cuenta para poder referirnos a los motivos que llevaron a unos y otros hacia la identificación con alguno de los bandos en el conflicto. Una breve referencia sobre del significado de la carrera militar en este período nos puede permitir comprender el grado de autonomía con que contaba un oficial del Ejército a la hora de proceder militarmente. En teoría, el horizonte de acción de estos jefes y oficiales estaba sostenido en la obediencia hacia los mandos superiores y la autoridad suprema del Presidente en su rol de Comandante en Jefe, una función ejercida de modo efectivo, no puramente nominal. Pero encontramos que el servicio de las armas se complementaba con la actuación política, o se subordinaba a la pertenencia de un partido o facción en la contienda política. Esta profesión entonces no era incompatible con otras funciones $\mathrm{y}$, como hemos visto, todavía carecía de la formación profesional sistemática y de un escalafón jerárquico bien definido. La carrera de las armas aparece inevitablemente relacionada con un orden social en el que la militarización de la política era un fenómeno naturalizado desde las guerras de la independencia. El llamado "espíritu de cuerpo" no estaba bien asentado, mientras para algunos el sentido de pertenencia a la institución militar lo era todo, para otros podía aparecer como una de sus diversas identidades. De modo que las decisiones motivadas por lealtades personales coexistían con la

\footnotetext{
${ }^{14}$ Las demandas indígenas por las tierras se identificaron con la restitución del gobernador depuesto Sánchez de Bustamante, el mitrismo y la revolución. Según un informe de la época la invasión se hacía al grito de "Viva el General Mitre i D. Teófilo Sánchez de Bustamante" (Paz, 2010: 171).

${ }^{15}$ La trayectoria posterior de la provincia en: Paz (2009).
} 
idea de disciplina y subordinación a los mandos político-militares. Ignacio de Fotheringham, un oficial que se mantuvo leal al gobierno, se refería a esta particularidad al señalar que "el general Arredondo creía que era un deber de sus amigos todos acompañarlo en su cruzada política. Que si no lo acompañábamos no éramos sus amigos. Raciocinio falso, lamentablemente falso [...] jamás dejé de ser su amigo [...] le debía muchas atenciones y servicios [...] pero sobre la amistad y sobre todo, prima el deber" (Fotheringham, 1999 [1909]: 284).

En el marco de la rebelión mitrista debemos señalar que respecto de los líderes militares que se alinearon en los bandos observamos ciertas notas en común que pueden darnos algunos indicadores para analizar. A simple vista, la comparación de los cuadros superiores de ambas fuerzas nos muestra una marcada diferencia generacional y de experiencia guerrrera. Examinando la trayectoria de los oficiales que adhirieron a la revolución se puede identificar alguna conexión de experiencias entre Ignacio Rivas (47 años), José María Arredondo (42), Andrés Gelly y Obes (59), Santiago Baibiene (36), Julián Murga (54), Benito Machado (51), Matías Ramos Mejía (64), Jacinto González (62), Nicolás Ocampo (50), Plácido Laconcha (circa 40), Ignacio Segovia (40). Muchos oficiales veteranos -mayores de 40 años o nacidos antes de 1840- y figuras cuya aparición pública está relacionada al surgimiento del partido liberal. Que fueron parte de la antigua camada del ejército que luchó contra Rosas, luego frente a la confederación urquicista en Pavón y más adelante en las campañas al interior del país en 1862-1863 que permitieron el ascenso de Mitre a la presidencia. Por el otro lado, la oficialidad que se mantuvo leal al gobierno de Sarmiento estaba mayormente compuesta por militares más jóvenes -en su mayoría no pasaban de los 40 años- cuyo bautismo de fuego y posterior ascenso se produjo en la larga campaña del Paraguay. Allí estaban Manuel Olascoaga (39), Napoleón Uriburu (38), Leopoldo Nelson (38), Rufino Ortega (37), Luis María Campos (36), Hilario Lagos (34), Eduardo Racedo (31), Ignacio Fotheringham (31), Octavio Ruiz Moreno (31, Julio Argentino Roca (30). Solo los coroneles Amaro Catalán (42), Juan Ayala (42) y Julio Campos (40) superaban los cuarenta años. ${ }^{16}$

Respecto del esquema antes propuesto que divide y separa a las lealtades de tipo faccioso de una forma de obediencia impersonal es interesante retratar la postura asumida por el coronel Borges una vez iniciado el conflicto. Su conducta parece personificar la superposición entre un modelo de compromiso con el ejército como institución del Estado y otro arquetipo de lealtad más personalista. El propio Borges asume la contradicción en que se encuentra cuando al sumarse a los revolucionarios, primero le asegura a su jefe, el

\footnotetext{
16 Sobre las polémicas que enfrentaron entre sí a oficiales del Ejército durante la campaña de Entre Ríos en 1870 y que anticipan esta división en 1874: Codesido (2014).
} 
presidente Sarmiento, que las fuerzas de línea que conduce no se unirán al movimiento revolucionario, con lo cual su comportamiento responde al primer modelo. ${ }^{17}$ Entonces, cuando el gobierno le ordenó entregar su regimiento al coronel Julio Campos, Borges obedeció persuadido de no alzar a su tropa contra el presidente Sarmiento. No obstante, el coronel también había empeñado su compromiso personal con el mitrismo. Para cumplir con ambos deberes se unió a los revolucionarios al día siguiente de finalizada la presidencia de Sarmiento, con lo cual sufrió el escarnio y las infamias de unos y otros. Sus compañeros revolucionarios, que estaban inmersos en la lucha, reprocharon su tardanza y el hecho de no haberse sublevado junto a su tropa, mientras que para el gobierno fue considerado un conspirador en las sombras. Florencio Del Mármol dirá que fue la carta del presidente Sarmiento la que persuadió a Borges de no entregar sus fuerzas a la revolución y agrega que "desde un principio el coronel Borges, hombre de carácter débil, no había inspirado confianza en los directores del movimiento revolucionario" (Del Mármol, 1876: 79). En definitiva, Borges fue puesto al mando de una fuerza revolucionaria de caballería sin experiencia ni instrucción. Durante la batalla de La Verde, al ver que el ejército de Mitre era destrozado en combate, y cuando el combate estaba ya perdido, se separó de sus hombres y atacó de frente contra la línea de tiradores del teniente coronel José Inocencio Arias, resultando herido de muerte. ${ }^{18}$

17 "Cuente conmigo y las fuerzas que yo mando no serán jamás rebeldes". Fue la respuesta de Borges a Sarmiento del 29 de septiembre. Sarmiento ante la sospecha de saberlo parte de la revolución le aconsejaba desistir de ello: "Oiga a un amigo: Si alguna prenda hubiera Vd. Comprometido, yo le doy mi palabra de honor, que ateniéndome en adelante à la que el deber le prescribe, y obedeciendo al Gobierno, quedará Vd. En la misma situación de antes. Cuando nos veamos le mostraré los documentos en que los conspiradores, para dar seguridad y confianza a los que intentan seducir, consignan su nombre". Sarmiento a Borges, 26 de septiembre. (Del Mármol, 1876: 530-532).

${ }^{18}$ La leyenda sobre su figura ha asegurado desde entonces que el coronel Borges se había hecho matar debido a la incomprensión de la que fue víctima por parte de los dos bandos. Dice Eduardo Gutiérrez: "Sus compañeros no comprendieron, o aparentaron no comprender aquel hermoso rasgo de caballerosidad y de carácter, reprochando a Borges, aunque no de frente y con claridad, lo que ellos se permitían llamar su traición. Y esto hizo una impresión terrible en aquel carácter esencialmente hidalgo y abnegado, concibiendo tal vez entonces la idea de hacerse matar [...] El gobierno y sus amigos políticos han sido para con él cruelmente ingratos" (Gutiérrez, 1960 [1886]: 43-45). Francisco Borges fue además abuelo del escritor J.L. Borges. Este le dedicó un poema en el que describe la actitud de su abuelo ante la muerte:

"Alusión a la muerte del Coronel Francisco Borges (1833-74)

Lo dejo en el caballo, en esa hora;

Crepuscular en que buscó la muerte;

Que de todas las horas de su suerte

Esta perdure amarga y vencedora..."

(Borges, 1960: 34-35) 


\section{Las disputas por la tropa}

La rebelión, inicialmente concebida para el mes de octubre se precipitó el 24 de septiembre luego del secuestro de las dos cañoneras y ello permitió al gobierno nacional acelerar los preparativos militares. El mismo 24 se declaró por ley del Senado y la Cámara de Diputados de la Nación el estado de sitio por 60 días en las provincias de Buenos Aires, Santa Fe, Entre Ríos y Corrientes, y se autorizó al Poder Ejecutivo Nacional para "movilizar en toda la República las Milicias que crea necesarias para mantener el orden público" (Domínguez, 1898: 477). La Cámara de Diputados de la provincia de Buenos Aires autorizó el mismo día la reunión y movilización de la milicia provincial y el gobernador provisorio Álvaro Barros ordenó por decreto, también el día 24, la movilización de la Guardia Nacional en toda la provincia (Domínguez, 1898: 478). El 26 de septiembre se nombra por decreto presidencial "Comandante en Jefe de toda la Guardia Nacional movilizada en la Provincia de Buenos Aires, el Teniente Coronel D. Adolfo Alsina" (Domínguez, 1898: 481). El mismo día 26 llegaron las novedades de San Luis, con el levantamiento de Arredondo y la noticia del asesinato del general de la Nación Teófilo Ivanowski ocurrida el 24 en Villa Mercedes. ${ }^{19}$

En Buenos Aires durante los siguientes días se publicaron en la prensa las órdenes de reunión de los distintos batallones de guardias nacionales indicando los lugares y momentos de presentación. Se insiste en el carácter obligatorio del servicio de armas requerido, señalando que quienes no asistieran al llamado serán sancionados. El gobernador Barros dictó dos decretos estableciendo, por un lado, que los enrolados ausentes en el término de 24 horas serían destinados a un cuerpo de línea y, por el otro, la prohibición de salir del territorio de la Capital sin una orden de la comandancia general de Guardia Nacional ${ }^{20}$ (Cordero y Barbuto, 2012: 153-171). Luego, Barros se dio a la tarea de crear cuatro nuevos batallones de Guardia Nacional en Campaña compuestos por 400 plazas cada uno para formar una división de reserva que pondría al servicio del gobierno nacional. Posteriormente, por decreto del nuevo presidente Avellaneda, se estableció la organización de un ejército de

\footnotetext{
${ }^{19}$ Con esta noticia se amplía la declaración del estado de sitio sobre toda la república el día 26 (Bragoni, 2010: 29-60). El gobierno nacional formó el 28 de septiembre al llamado Ejército del Norte que puso al mando del coronel Julio A. Roca para actuar en el interior. El 5 de octubre dispuso la formación del Ejército del Oeste a las órdenes de Luis María Campos y colocó a su hermano Julio Campos al frente del Ejército del Sur. Estas dos últimas fuerzas actuarían en la provincia de Buenos Aires.

${ }^{20}$ Barros acordó que "todo Sargento, cabo y soldado de la Guardia Nacional que haya hecho la Campaña del Paraguay y tenga excepción del servicio, recibirá un premio de mil pesos moneda corriente, si voluntariamente ingresa á cualquiera de los Batallones movilizados, conservando su carácter de Guardia Nacional y su excepción cuando sea nuevamente licenciado". La medida se refiere a la ley de 1866 que concedía diez años de exoneración de todo servicio para los ciudadanos que combatieron en la guerra del Paraguay (Domínguez, 1898: 481).
} 
reserva de 15 mil plazas que debía formarse en Rosario con el aporte de cinco provincias (Domínguez, 1898: 494). La fuerza estaría al mando del coronel Ayala y se nombró al coronel Mansilla como Jefe de Estado Mayor y encargado del reclutamiento hasta alcanzar el número de plazas propuesto inicialmente. ${ }^{21}$

Durante todo el transcurso del movimiento revolucionario hubo soldados del Ejército de Línea y miembros de la Guardia Nacional en las fuerzas de uno y otro bando. Los mitristas en la campaña bonaerense contaron con la ayuda de algunos jueces de paz y jefes militares de sus partidos para poder "convocar" a los guardias nacionales. ${ }^{22}$ En este sentido, el desarrollo de la política fronteriza de Bartolomé Mitre durante su presidencia (1862-1868) instaló en los puestos militares a muchos de sus partidarios políticos. Fue muy importante la participación de los jefes militares sumados a la revolución, quienes pusieron en juego su autoridad en las zonas donde desplegaban su influencia. Aquí aparecen aspectos de la política local y el funcionamiento de las redes clientelares, lealtades facciosas y distintos mecanismos de negociación o de coacción utilizados por esos jefes en la tarea de reclutar a los paisanos de aquellas poblaciones (Cordero y Barbuto, 2012). ${ }^{23}$

La Guardia Nacional de las localidades de frontera constituyó el grueso del ejército rebelde; los documentos y crónicas de la época muestran que su movilización fue impulsada por la activación de redes previas que conectaban a las autoridades militares y a las elites locales con la población local (Barbuto y Cordero 2012). El general Rivas era la figura más importante del mitrismo en esta región y, según se sugiere en el trabajo de Barbuto y De Jong (2012), desde principios del año 1874 había indicios de que sus planes para ocupar Carhué y Salinas Grandes en realidad escondían los preparativos para el alzamiento militar. Las solicitudes de tropas, caballos y armamento habían provocado que el ministro Gainza desconfiara en ese mismo sentido. ${ }^{24}$ Cuando se pronunció el alzamiento el 24 de septiembre de 1874, Rivas puso en juego esos recursos y su influencia en la frontera para movilizar rápidamente las fuerzas de línea a su

${ }^{21}$ No fue necesaria la participación de esos refuerzos debido al creciente control que la contienda iba adquiriendo por parte de las fuerzas leales al gobierno.

${ }^{22}$ Leonardo Canciani (2017) retrata la participación de los jefes como Machado, Ramos Mejía y González, quienes gozaban de fuerte arraigo local en diferentes zonas de la campaña bonaerense y a espaldas del respaldo estatal, utilizaron mecanismos compulsivos y coactivos para garantizar el reclutamiento rebelde.

${ }^{23}$ Algunos trabajos que examinan las redes de poder local a partir de la figura de un jefe militar: Canciani (2012) Buchbinder (2005); Míguez (2011); Goldman y Salvatore (1998).

${ }^{24}$ Según Barbuto y De Jong: "Gainza se asombraba ante el pedido de Rivas de cañones y hombres para atenderlos, ya que al contar las tropas con fusiles Remington consideraba innecesarias las piezas de artillería. Rivas justificaba la necesidad de su pedido, no por temor a los indios, sino para dotar de artillería a los fuertes que se establecerían. Cuando días después Rivas acusaba recibo de dos piezas de artillería, reclamaba que no eran livianas como había pedido sino de un tipo poco apto para su traslado en campaña" (Barbuto y De Jong, 2012: 53$54)$. 
cargo, reunir a la Guardia Nacional y reclutar para su movimiento a las fuerzas del cacique Cipriano Catriel. ${ }^{25}$

Tanto las formas de movilización impulsadas desde el gobierno nacional y provincial, como los mecanismos utilizados por el movimiento rebelde, en la práctica involucraron situaciones de violencia asociadas con métodos compulsivos de reclutamiento. Muchos individuos de los distintos partidos de la campaña bonaerense en edad de participar -y otros que no alcanzaban la edad mínima requerida para ser un Guardia Nacional, los 17 años- fueron reclutados tanto en las fuerzas del gobierno como en las revolucionarias. Una incorporación a través de diversos mecanismos, siempre alejados de la voluntad del individuo para convertirse en soldado. Hemos podido acceder a examinar numerosas cartas de familiares, madres, padres, hermanos dirigidas a distintos jefes militares, jueces de paz o al ministerio de Guerra y Marina pidiendo por aquellos que, según se denunciaba, fueron enviados injustamente a servir en un cuerpo de línea a medida que se desarrollaba la guerra. El análisis de esas peticiones nos ha proporcionado material para analizar los mecanismos de incorporación compulsivos y algunas estrategias de resistencia de los sectores populares ante la presión reclutadora.

Durante los meses de noviembre y diciembre de 1874, a partir del desmembramiento de las fuerzas mitristas se hacen públicas diversas situaciones de abuso contra ciudadanos que componían la tropa de ambos bandos, junto con otras irregularidades que muestran la magnitud de la militarización y sus efectos sobre la población (Míguez, 2003:17-38). En las solicitudes que mencionamos se repite un tópico similar cuando los familiares de los individuos destinados a las fuerzas de línea aseguran que los mitristas los habían llevado a la fuerza antes, y ahora como castigo hace lo mismo el gobierno. Otras voces protestan por ser destinados al no haberse presentado al llamado a los cuarteles de la Guardia Nacional o luego de ser detenidos cerca de una partida enemiga. ${ }^{26}$ Un padre, Pantaleón Peñaflor reclama al Ministro de

\footnotetext{
${ }^{25}$ Rivas sustituyó a las autoridades civiles de Azul -que respondían al gobierno- por otras leales a la revolución y ello facilitó la organización de los contingentes de guardias nacionales, que fueron citados inmediatamente (Barbuto y De Jong, 2012: 54-56). Ingrid de Jong sobre la participación indígena en la revolución: "Creemos que el apoyo de los catrieleros a las fuerzas mitristas respondió a una situación compleja, en la que contaban tanto el poder concitado por Cipriano Catriel como los cuestionamientos a la autoridad del cacique, las expectativas de una compensación material y un razonamiento estratégico sobre la correlación de fuerzas en la frontera sur" (De Jong, 2012: 15).

${ }^{26}$ Teodora Segovia de Chivilcoy se dirige a la autoridad militar: "mi esposo José Ramírez se encuentra en servicio activo en el $2^{\circ}$ Batallón de la División de Reserva; y mi hijo joven que aún no tiene la edad para el servicio de las armas, Manuel Ramírez, en el Batallón 6 de Línea, sin haber cometido falta ni delito alguno por el que pudiera ser destinado al servicio de las armas", adjunta un certificado del Juez de paz de Chivilcoy que prueba su inocencia y concluye: "pido a Vd. que me conceda la baja de alguno de los dos, particularmente de mi hijo, que ha sido injustamente destinado á un Batallón de Línea". La respuesta será un informe del jefe del $6^{\circ}$ de
} 
Guerra por su hijo Rafael "menor de edad y oriental de nacionalidad", quien "se presentó voluntariamente al servicio de las armas sin la venia esencial de sus padres, que ejercen aun sobre él [...] la patria-potestad". ${ }^{27}$ Andrea Pérez pide por su hermano destinado a las fuerzas de Línea, acusado de estar implicado en la revolución y pide la opción de poner un personero "que haga las veces de mi hermano por el tiempo que corresponda" pues "es un padre lleno de familia y dueño de un pequeño establecimiento de campo y su presencia se hace indispensable para la administración y cuidado de aquella". ${ }^{28}$

Otros reclamos sobre la ilegalidad del gobierno en su afán reclutador se reflejan en el pedido de explicaciones por parte del consulado italiano sobre la situación de sus ciudadanos destinados a las fuerzas de línea como infractores de la ley de enrolamiento. La cuestión solo se hace visible cuando el damnificado tiene quien lo respalde luego de ser destinado. Sobre la situación de uno de ellos, la respuesta que recibe el consulado es que si "José Martini -el italiano destinado- es de aquellos que las leyes del país castigan con el servicio de las armas, no será posible atender á esta solicitud, puesto que dicha pena es de aplicación tanto á los nacionales como á los extranjeros". Luego de las averiguaciones se informa que "el individuo que reclama la delegación de Italia fue remitido por el Gobierno de la Provincia con otros destinados por infractores a la ley de enrolamiento, pero como resultó ser de nacionalidad Italiano el que reclama el Sr. Cónsul debe ser dado de baja del servicio". ${ }^{29}$ La repetición de esta práctica obligó al gobernador a emitir un decreto que exigía la liberación de extranjeros sin papeleta que demostraran su origen (Cordero y Barbuto, 2012: 160). Inversamente a la situación de los extranjeros destinados por faltar a la ley de enrolamiento, hubo casos de argentinos que buscando evitar el llamado a las armas presentaban papeleta extranjera para ser exceptuados del servicio. Las autoridades militares y políticas declaraban inadmisible que esos guardias nacionales nieguen sus servicios a la patria puesto que "cuando las instituciones peligran solo pueden ser salvadas por aquellos a quienes protege en épocas normales". ${ }^{30}$ Esas denuncias motivaron la

Línea -José I. Arias: “El individuo -Manuel Ramírez- para quien su señora madre pide la baja ha sido destinado por cuatro años por haber sido capturado en la revelion armada contra las autoridades de la Provincia en el partido de Chivilcoy". No se hace lugar al pedido de la madre y Manuel Ramírez continuará su condena en la fuerza de Línea. En Estado Mayor General del Ejército, Servicio Histórico, Organización Nacional (En adelante EMGE, SH, ON), Caja 50, 6 de septiembre-15 de octubre de 1874, Carpeta 248: Política interna y causas, folios 28-30, documento 15509.

${ }^{27}$ EMGE, SH, ON, Caja 51, 16 de octubre-30 de noviembre de 1874, carpeta 255: Organización de fuerzas y operaciones, folio 34, documento 15652.

${ }^{28}$ La solicitud aparece sin respuesta. EMGE, SH, ON, Caja 51, folios 41-42, documento 15665.

${ }^{29}$ EMGE, SH, ON, Caja 50, Carpeta 251: Organización y operaciones, folios 65-68.

${ }^{30}$ De forma similar, otro italiano Tomás Petitte "fue tomado preso en viaje de Chivilcoy al 25 de mayo, por carecer de papeleta"; hechas las averiguaciones es puesto en libertad el 22 de febrero de 1875. EMGE, SH, ON, Caja 52: diciembre de 1874, Carpeta 258: Política interna y causas, 
intervención del gobernador Álvaro Barros, dada por la gravedad de actos que incluían el accionar de distintos consulados. ${ }^{31}$ Otro ciudadano, Gregorio Rodríguez, detenido desde el 6 de octubre en una comisaria de Buenos Aires, fue encontrado "prófugo huyendo de los rebeldes". Rodríguez declara que:

"Pasó al exterior del Riachuelo de la Boca, trabajando en su oficio de pescador. $2^{\mathrm{o}}$ Fue allí detenido por el escribano Don José Fernández, presidente del Club mitrista de San Telmo, a la cabeza de noventa hombres armados de fusil. $3^{\text {o }}$ Entre esa gente reconoció á Roque Vila, carrero -carretero-, domiciliado en la calle Garay no 30 . 4º Que cuando las fuerzas del Gobierno fueron á aprehender los rebeldes, el escribano Fernández les mandó que se dispersaran y se ocultaran en los pajonales, hasta que él los llamara, y que si los encontraban pelearan y no se rindieran. 5o Que recién y con ese objeto el declarante fue puesto en libertad, pues lo tenían arrestado". ${ }^{32}$

Rodríguez pudo escapar de los rebeldes y se presentó a declarar según el informe del comisario al Ministro de Guerra. ${ }^{33}$ En estos testimonios observamos que la guerra también alteraba la vida de muchos individuos y sus familias que subsistían al margen de las redes de protección de la sociedad local. Cuando no quedaba otra opción, solo restaba decidir de quien huir y ante quién presentarse, para no ser arrastrado por la fuerza. De esa situación da cuenta Julio Campos al nuevo Ministro de Guerra Alsina; afirma que en los alrededores de los partidos de Juárez y Ayacucho hay "muchos individuos dispersos que andan huyendo de la montonera más bien que de la fuerza de la

Documento 16052, 11 de diciembre de 1874. Vale recordar que la ley de enrolamiento establecía que solo los ciudadanos argentinos son Guardias Nacionales.

${ }^{31}$ Desde el ministerio provincial se describía el modus operandi de aquellos que evadían el servicio: "el abuso que cometen los malos ciudadanos negando su patria tiene por causa el régimen establecido en los consulados para el otorgamiento de las papeletas. En los consulados no se les exijen partida de bautismo ni ninguna justificación escrita, concretándose los empleados a recibir prueba testimonial. [...] Todo aquel que no quiere cumplir el deber de ciudadano, lleva al Consulado dos individuos sin delicadeza, que por dinero o por amistad, presten declaraciones falsas, y conviertan a un argentino desertor, en un hijo de España, ó de Italia etc. [...] hay casos en que los cónsules dan papeleta con la afirmación de un solo testigo, como en el incidente de Costa, desertor también del 50 Regimiento". EMGE, SH, ON, Caja 52, Carpeta 258: Política interna y causas, Documento 16052, folio 50.

32 EMGE, SH, ON, Caja 50, Carpeta 248: Política interna y causas, folios 32-34, documento 15509 bis.

${ }^{33}$ El relato del paisano Contreras a su amigo Maldonado en los versos citados al principio de este capítulo encuentra muchas similitudes con las declaraciones de Gregorio Rodríguez. Ambos fueron sorprendidos por miembros de la facción revolucionaria cuando iban en camino hacia sus labores diarias. 
Nación". ${ }^{34}$ Se sorprende al comprobar que "se presentan -se alistan en su fuerza- a la primera oportunidad que se les ofrece" ${ }^{\prime 3}$ Cerca de allí, la marcha de las fuerzas mitristas por Tandil y la resistencia pacífica de una corporación municipal, compuesta por mayoría de extranjeros, que se cuidó de no sumarse a ninguno de los bandos en pugna también da cuenta de las resistencias de los pobladores de la campaña bonaerense. ${ }^{36}$

A partir del mes de noviembre se intensifica la fuga de individuos de las fuerzas revolucionarias que se van presentando a las del gobierno. Esos sujetos se convierten en fuente de información acerca de los movimientos del enemigo y el estado de sus fuerzas. Julio Campos informa al Ministro desde azul el 21 de noviembre: "la declaración tomada al individuo Cecilio Funes, que se me presentó con 6 hombres fugados de la fuerza de la revuelta [...] declara que él es venido de azul y que después de haber sido llevado por los rebeldes, fue nombrado alférez". Luego de informar la posición del enemigo "agrega el declarante que la columna enemiga no tiene más que 2500 hombres en completa desmoralización -Que Rivas antes marchaba á la cabeza del ejército, ahora va al centro de la columna [...] Que el ejército parece más grande cuando acampa porque hacen grandes fogones". ${ }^{37}$ Estos reportes aparecían a fines del mes de noviembre en diarios como La República y La Tribuna. La publicación de esta información tenía el propósito de poner en conocimiento al público propio, interesado sobre el estado del conflicto, del desbande que estaban sufriendo las fuerzas revolucionarias y los atropellos que los rebeldes cometían en los parajes donde transitaban. A su vez, como los periódicos circulaban en las zonas de influencia rebelde jugaban su papel en la estrategia de la desmoralización final del Ejército Constitucional. A esa altura las referencias hacia las fuerzas mitristas oscilaban en torno a la idea de bandas que "van más bien en fuga que marchando" y son la "montonera infame -que- huye despavorida y á la sola presencia de nuestros bravos no se paran un instante". ${ }^{38}$

\footnotetext{
${ }^{34}$ EMGE, SH, ON, Caja 51, Organización Nacional, Carpeta 255: Organización de fuerzas y operaciones, folios 28-29, documento 15653.

${ }^{35}$ Enseguida envía comisiones - de unos treinta soldados y un oficial al mando- con el objetivo de reclutar a esos individuos dispersos en otros partidos como Dolores y en las cercanías de este. Ello sucedía a mediados de octubre.

36 "Nosotros no tenemos incidencia en las cuestiones políticas de este querido país que respetamos, pero nuestros intereses, que están aquí, son intocables", argumentarán ante el propio Mitre reunidos en el salón municipal. Eduardo Míguez (2011: 59-60) reconstruye el paso de los mitristas por Tandil a partir de las memorias de Juan Fugl, un inmigrante danés que presidió aquella corporación municipal.

${ }^{37}$ Diario La República, 25 de noviembre de 1874. Reporte del Ejército del Sud, 21 de noviembre de 1874. En AGN, Sala VII, Archivo del señor J. Biedma, revolución de septiembre de 1874, Documento 1038, sin paginación.

38 Diario La Tribuna, 18 de noviembre de 1874, Carta del corresponsal del diario al redactor, en AGN, Sala VII, Archivo del señor J. Biedma, revolución de septiembre de 1874, Documento 1038.
} 


\section{A modo de balance}

La rebelión mitrista y su desenlace militar forman parte del proceso de construcción estatal que separa a sus actores en uno u otro bando de la contienda. El mitrismo no se proponía hacer una revolución en el sentido de modificar las reglas de juego del sistema político (Míguez, 2011: 180-205). Los principios políticos de la insurrección se asociaban con la resistencia frente a la arbitrariedad y la tiranía (Sabato, 2009: 174). La estrategia del mitrismo se basaba en vínculos construidos por lealtades personales y en alianzas territoriales previas que permitirían contar con el apoyo de jefes militares del Ejército Nacional y las fuerzas de su mando. Los estudios sobre la conformación de redes clientelares y la dinámica impuesta por la lucha de facciones en las sociedades de frontera nos han servido para comprender el lugar de la población subalterna en aquellas movilizaciones. Hemos podido observar cómo la guerra alteraba la vida de muchos pobladores que subsistían apartados de los tejidos de poder local y quedaban a merced de los mecanismos de reclutamiento forzoso propios de una sociedad militarizada. ${ }^{39}$

Los grupos de oposición dentro de la estructura de poder vigente cuentan con el poder militar suficiente para utilizar la vía armada en la resolución de los conflictos políticos. La cuestión del monopolio de la fuerza todavía está por decidirse en un contexto de militarización de la vida política donde los miembros del gobierno y quienes aspiran a desplazarlos consideran que la capacidad de movilizar recursos humanos para las fuerzas armadas es una de las expresiones fundamentales de la política partidaria. Un fenómeno que se construye a partir de tejidos de poder que dependen de vínculos basados en lealtades personales. En este sentido hemos podido verificar que las diversas variantes que asume la incorporación de recursos humanos y materiales, en uno y otro bando, muestran las ventajas con que cuentan quienes actúan en nombre del gobierno vigente. Ello es un indicador de que las instituciones del Estado nacional, asociado al provincial en este caso, consiguen obtener en el plano militar una mayor efectividad que la alcanzada por el movimiento opositor. Por otra parte, la victoria de las fuerzas nacionales sobre las fuerzas rebeldes es un triunfo del ejército regular sobre las fuerzas "montoneras" o irregulares ${ }^{40}$, que

\footnotetext{
${ }^{39}$ También pudimos verificar que la propia dinámica del ejercicio del poder el contexto de movilización engendraba diversos mecanismos de resistencia por parte de los sectores subalternos.

${ }^{40}$ El resultado de la Batalla de La Verde, librada al sur de la provincia de Buenos Aires se produjo por la mejor instrucción y disciplina de las fuerzas de línea. Según el historiador militar Augusto Rodríguez: "el fuego nutrido y regular del 6 de línea, cuyos soldados habían adquirido práctica en el manejo del Remington en la campaña a Entre Ríos contuvo la enérgica embestida de los rebeldes [...] Arias dispuso de 572 fusiles Remington y 210 carabinas de caballería a pistón; los rebeldes 1500 fusiles y carabinas Remington y 400 Martin Henry, tan buenas o
} 
además, en términos militares, expresa el triunfo de la instrucción y la disciplina sobre la "estrategia del número". ${ }^{41}$

La rebelión del mitrismo es importante dentro de la historia de las fuerzas armadas porque en esta contienda vuelve a ponerse en cuestión la dimensión facciosa de sus órganos. El Ejército como actor político además de sostener el orden legal, respondiendo al mando del presidente saliente y al de su sucesor, luchará por desprenderse de la sombra que lo persigue desde su institucionalización como fuerza nacional: la de su propio origen faccioso relacionada con la época de apogeo del mitrismo. En ese sentido, uno de los significados asociados con la derrota de los rebeldes consiste en despegar la imagen del ejército de la facción mitrista del Partido Liberal. Ahora su fisonomía aparecería vinculada con una nueva camada de oficiales más identificada con la profesión militar que sirve de modo impersonal al Estado, cuyo bautismo de fuego y posterior ascenso se produjo durante la campaña del Paraguay (1865-1870). Este conflicto internacional tuvo una incidencia decisiva en la transformación de las fuerzas argentinas en Ejército Nacional (Garavaglia, 2016: 131) y la oficialidad modelada en esa experiencia emergerá como un actor social con peso propio. En las operaciones militares que enfrentaban a las facciones partidarias también se hacían visibles las divisiones existentes en el seno del Ejército. ${ }^{42}$

Desde 1868, la presidencia de Sarmiento se había propuesto la despolitización de las fuerzas armadas a través de un proceso de profesionalización del cuerpo de oficiales, tendiente a fortalecer la disciplina que produce la subordinación impersonal del soldado hacia el Estado. Desde esta perspectiva, los oficiales serán eslabones de una jerarquía de mandos gobernada por el Comandante en Jefe del Ejército y cara visible del Estado nacional, el presidente de la república. De modo que la profesionalización del

superiores a la Rémington. Pero indudablemente, tales armas requerían experiencia en su manejo, especialmente en la utilización del alza, de lo que carecía la masa de las tropas reunidas por Mitre" (Rodríguez, 1964: 61)

41 Roca reflexionaba en 1875 sobre la Triple Alianza: "Aquella guerra que pudo ser buena escuela para nuestros oficiales [...] se hizo como todas nuestras cosas a la ventura [...] esta duró tanto, porque ni en nuestros generales, ni en los brasileños, ni en el campo paraguayo, hubo la chispa militar necesaria. De una y otra parte la estrategia ha consistido en amontonar gente; el primero á quien se le agotaba esta tenía que sucumbir. Así fue. Los paraguayos se agotaron primero. Nosotros triunfamos". Carta de Roca a Sarmiento, publicada en el diario La Tribuna el 4 de agosto de 1875.

42 Los actos de justicia militar también aparecen atravesados por enfrentamientos personales. Julio Campos, al ser designado integrante del consejo de guerra que juzgará a Arredondo, escribe a Alsina: "un deber de conciencia, Sr. Ministro, me pone en la condición imprescindible de declinar el nombramiento hecho en mi persona, por cuanto es notoria la enemistad personalísima en que me encuentro con el General Arredondo". Campos a Alsina, 21 de diciembre de 1874. EMGE, SH, ON, Caja 52, Carpeta 257: Política interna y causas, Folio 86, Documento 16147. 
Ejército se asocia con el proceso de centralización (Macías, 2018: 233). La formación académica de los oficiales del Ejército de Línea expresada en la creación del Colegio Militar de la Nación se funda en estos objetivos. ${ }^{43}$ Para esta concepción de las fuerzas armadas, el mitrismo en su vertiente militar no solo se vinculaba con su orientación partidaria, sino que representa a una época anterior a la década de 1870 . Un período en el cual las relaciones de mando y obediencia no estaban del todo establecidas y los jefes del Ejército de Línea actuaban con considerable autonomía del poder central (Macías, 2018: 232). ${ }^{44}$ La política militar que propone Sarmiento intentará separar esas prácticas basadas en relaciones personalistas por un modelo burocrático que prepare oficiales para responder de manera impersonal al Estado nacional y sobre ese desafío plantea la fundación de la academia militar. En septiembre de 1872 el Congreso de la Nación había sancionado la ley para el reclutamiento del ejército donde se apuntaba a transformar al Ejército de Línea en pilar del Ejército Nacional. En ella se establecían las condiciones para el alistamiento de voluntarios, enganchados, destinados y la proporción del número de reclutas en forma de contingente con que cada provincia debía contribuir al servicio de la nación. ${ }^{45}$

Una vez concluido el conflicto de 1874 y a partir de la llegada de un nuevo gobierno nacional, los efectos de la guerra promovieron nuevas configuraciones en una organización militar que debía afianzarse junto con el Estado nacional (Oszlak, 1982; Tilly, 1993). La actividad bélica y su continuidad en la política (Foucault, 1996) derivaría en la depuración de los cuadros del Ejército, soltando el lastre mitrista representado por los generales Rivas, Gelly y Obes, Arredondo y otros personajes como el coronel Machado. ${ }^{46}$ Una vez que el movimiento rebelde fue controlado, la gestión de Avellaneda se iniciará con el juzgamiento de los jefes militares del mitrismo. Por decreto del 18 de diciembre

\footnotetext{
${ }^{43}$ En octubre de 1873 se graduaría la primera camada de estudiantes, un total de 13 oficiales. A raíz de la segunda guerra contra López Jordán, cuatro alumnos de $4^{\circ}$ año fueron movilizados por orden del ministro Gainza para completar el cuadro de oficiales del Regimiento $1^{\text {o }}$ de Caballería. En la misma fecha el gobierno entregó los despachos de subteniente al resto de los alumnos del $4^{\circ}$ año y así los primeros egresados del Colegio se integraron al ejército.

${ }^{44}$ En este sentido la figura de Arredondo aparece más ligada con la de un jefe indisciplinado, poco profesional y alejado del perfil del oficial subordinado al Estado, antes que asociado con el partido de Mitre y su causa.

${ }^{45}$ Fue la primera disposición que adecúa los contingentes requeridos, con la población existente en cada provincia según el censo nacional de 1869. Establece el sistema de sorteo entre todos los hombres de 18 a 45 años. Argentina. Ejército, Ley de reclutamiento, Imprenta Americana, Buenos Aires, 1872, folleto de 14 páginas. En 1872 también se crea la Escuela Naval que comienza a funcionar a bordo del buque de guerra General Brown.

46 Arredondo fue otro de los denunciados públicamente por Álvaro Barros entre 1870 y 1872, quien en su momento recopiló testimonios y evidencias de corrupción en su desempeño como jefe de la Frontera de Córdoba. Se lo acusaba de traficar con los sueldos de los soldados, recibir provisiones y dinero según listas de revista infladas con soldados inexistentes. A Machado le dedica un capítulo de su libro (Barros, 1957 [1872]) donde repasa los modos por los que este jefe se enriquecía.
} 
de 1874, el presidente ordenó iniciar el proceso de justicia militar contra los oficiales rebeldes vencidos en "La Verde" y "Santa Rosa" con la constitución de dos consejos de guerra de oficiales generales. ${ }^{47}$ El 30 de abril de 1875 se publica la sentencia del consejo de guerra para los oficiales rendidos en Santa Rosa, las condenas van desde los 2 hasta los 6 años de prisión para algunos y la pena de muerte contra Arredondo. (Domínguez, 1898: 528). El 24 de mayo se conoce la sentencia contra los jefes de línea rendidos en Junín. ${ }^{48}$ La medida venía acompañada por una serie de consideraciones que hace Avellaneda declarando la voluntad de "conciliación y de clemencia" que sostiene el gobierno, aunque también "debe hacer sentir alguna represión respecto de los jefes que, ejerciendo mandos superiores, abusaron de ellos" (Domínguez, 1898: 530). Finalmente, los procesados serán indultados por la ley de amnistía aprobada el 26 de julio de 1875. En ella se concede "amnistía general por todo delito político anterior a la presente ley" (Domínguez, 1898: 533). La medida propiciará una serie de gestiones tendientes a crear la idea de la Conciliación de los partidos. A partir de 1876 empezaron a hacerse visibles las aproximaciones entre el gobierno nacional y los mitristas cuando Avellaneda anunció en su tercer mensaje presidencial que ya podían volver libremente al país todos los proscriptos por la revolución de septiembre. Para completar esa sucesión de expresiones de buena voluntad solo faltaría que los jefes militares dados de baja del Ejército, sujetos a consejo de guerra y luego amnistiados en 1875, sean reincorporados y esa disposición llegará por decreto presidencial el 24 de mayo de 1877. Ese año retornaron al país Rivas y Arredondo, entre otros, para ser reincorporados al ejército. A Rivas se le otorgó el alta en la plana mayor, pero sin mando de tropas y no participó luego en la Campaña al Desierto. Otra lista de jefes y oficiales fue definida a partir de un acuerdo que prestaba el Senado Nacional al presidente, elevando los nombres de quienes serían reincorporados. ${ }^{49}$

\footnotetext{
${ }^{47}$ Allí serán "juzgados con arreglo a las leyes militares los jefes y oficiales de línea que tomaron parte en la rebelión iniciada el 24 de septiembre último de conformidad con lo dispuesto en el artículo $7^{\circ}$ de la ley de septiembre de 1863 sobre jurisdicción y competencia de los tribunales federales y de acuerdo con lo dispuesto en el artículo $1^{\circ}$, título 6 , tratado 8 de las Ordenanzas" (Domínguez, 1898: 504).

${ }^{48}$ Fue revisada por Avellaneda y sus penas atenuadas: “El ex-Brigadier D. Bartolomé Mitre y los ex-Coroneles D. Jacinto González, D. Emilio Vidal y D. Martiniano Charras, serán puestos en libertad, declarándose compensada respecto de ellos, con la prisión sufrida, la pena de ocho, seis y tres años de destierro á que han sido condenados por el Consejo de Guerra. El ex-General D. Ignacio Rivas, ex -Comandante en Jefe de las Fronteras del Sud, los ex-Coroneles D. Nicolás Ocampo, ex-Jefe de la Frontera Sud y D. Julián Murga, ex-Jefe de la Frontera de Bahía Blanca y Patagones, saldrán del país por dieciocho meses, en vez de los ocho años de destierro a que han sido condenados" (Domínguez, 1898: 530).

${ }^{49}$ También fue indultado B. Machado, reincorporado al ejército, sin mando de tropa. I. Segovia fue pasado a la Plana Mayor disponible en 1878 junto con otros antiguos jefes mitristas como J. González y P. Laconcha. Machado participó en la revolución encabezada por tejedor en 1880 y
} 
En 1877 el mitrismo se reincorporaba al escenario político, pero dejando atrás el antiguo poderío militar representada en sus antiguos jefes, que volverán al Ejército en lugares menos relevantes. ${ }^{50}$ De este modo, la rebelión mitrista es un acontecimiento que revela el aspecto militar de la "agonía de la lucha de facciones tradicional" que describía Halperín Donghi (1982: 138-145), donde el disenso armado comienza a perder las posibilidades de triunfar sobre un ejército que expresa el creciente poder del Estado nacional, fenómeno que terminará por confirmarse luego de la guerra de 1880 con el triunfo del poder militar centralizado. ${ }^{51}$

Buenos Aires, diciembre de 2020

\section{Bibliografía citada}

Barbuto, Lorena y De Jong, Ingrid (2012). “De la defensa de las fronteras al conflicto faccional. Preparando la revolución mitrista en el sur de Buenos Aires (1872-1874)", en Sociedades de paisajes áridos y semi-áridos, núm. 5, pp. 35-65.

Barros, Álvaro (1957) [1872]. Fronteras y territorios federales de las Pampas del Sur, Buenos Aires: Hachette.

Borges, Jorge Luis (1960). El Hacedor, Buenos Aires: Emecé.

Bragoni, Beatriz (2010). “Cuyo después de Pavón: Consenso, rebelión y orden político, 1861-1974”, en Bragoni y Míguez (2010), pp. 29-60.

Bragoni, Beatriz y Míguez, Eduardo (2010). Un nuevo orden político, Provincias y Estado Nacional, 1852-1880 (pp. 29-60), Buenos Aires: Biblos.

Buchbinder, Pablo (2005). “Estado caudillismo y organización miliciana en la provincia de Corrientes en el siglo XIX: El caso de Nicanor Cáceres", en Revista de Historia de América, núm. 136, pp. 37-64.

fue nuevamente dado de baja. Tres años después, a los 60 años, fue dado de alta para acceder a la jubilación. Reincorporar a Arredondo requería antes expedirse sobre la condena a muerte que pesaba sobre él. El nueve de junio de 1877 -por decreto- se deja sin efecto la pena capital "de conformidad con la política de conciliación y de olvido que el gobierno ha proseguido" (Codesido, 2020).

50 Durante las semanas posteriores a la publicación de los indultos, otros oficiales de menor jerarquía escribirían al Ministerio de Guerra solicitando ser reincorporados al ejército. En la mayoría de los casos esos pedidos fueron aceptados y los oficiales puestos nuevamente en funciones conservando el mismo grado militar que tenían antes del levantamiento del 24 de septiembre de 1874. Varios casos en EMGE, SH, ON, 1877, Cajas 67 y 68, Política Interna y causas, documentos 18726 y 18840.

${ }^{51}$ Desde la aparición del roquismo habrá de perder protagonismo la vinculación entre la política y la guerra, cobrando mayor relevancia la búsqueda de "consensos" que producen nuevas configuraciones en las relaciones entre las dirigencias nacionales y provinciales transformando la trama política de las facciones/partidos en torno de la lucha política nacional (Cuchi, 2015). 
Canciani, Leonardo (2012). “El coronel Don Benito Machado. Un comandante de Guardias Nacionales en la frontera sur bonaerense (1852-1880)", en Mundo Agrario, vol. 12, nº 24, sin pp.

Canciani, Leonardo (2017). “ "Yo también os digo á las armas». Comandantes de la Guardia Nacional y caudillos mitristas en la revolución de 1874", en Revista Historia y Política, $\mathrm{n}^{\circ} 37$, pp. 211-240.

Codesido, Lucas (2014). "Militarización de la política y política de guerra en el Ejército argentino (1870) durante el proceso de construcción del Estado", en Historia Caribe, Colombia, Volumen IX, nº 24, enero-junio, pp. 131-161.

Codesido, Lucas (2019). “Delincuentes, mercenarios y ciudadanos. La política militar de Alsina y el avance de la frontera (1874-1877)", en Antigua Matanza, vol. 3, n5, junio-diciembre, pp. 6-45.

Codesido, Lucas (2020). El proceso judicial a los rebeldes mitristas. Entre la tradición militar española y la Conciliación de los partidos (1874-1877), en Pasado Abierto (en prensa).

Cordero, Guido (2013). “La administración fronteriza y la construcción de redes políticas: Frontera sur de Buenos Aires, décadas de 1860 y 1870", en Memoria Americana 21 (1), enero-junio, pp. 39-63.

Cordero, Guido y Barbuto, Lorena (2012). “La movilización de los sectores subalternos en la revolución mitrista de 1874", en Anuario del Centro de Estudios Históricos "Prof. Carlos S. A. Segreti", año 12, n 12, pp. 153-171.

Cucchi, Laura (2015). Antagonismo, legitimidad y poder político en Córdoba, 18771880, Bahía Blanca: Editorial de la Universidad Nacional del Sur.

Daghero, Sergio (2014). "Las facciones y las armas. la Revolución de 1874 en Córdoba y Cuyo", en Coordenadas, año 1, n¹, pp. 118-142.

De Jong, Ingrid (2012). "Facciones políticas y étnicas en la frontera: los indios amigos del Azul en la Revolución Mitrista de 1874", en Nuevo Mundo Mundos Nuevos, vol. 1, pp.1-19.

Del Mármol, Florencio (1876). Noticias y documentos sobre la revolución de setiembre de 1874, Buenos Aires: Imprenta de M. Biedma.

Domínguez, Ercilio (1898). Colección de leyes y decretos militares, Tomo segundo, 1854-1880, Buenos Aires: Compañía Sudamericana de Billetes de Banco.

Fotheringham, Ignacio (1999) [1909]. La vida de un soldado o reminiscencias de la frontera, Buenos Aires: Ciudad Argentina, 1999.

Foucault, Michel (1996). Genealogía del racismo, Buenos Aires: Caronte Ensayos.

Garavaglia, Juan Carlos (2012). "Fuerzas de Guerra y construcción estatal: de la Confederación a la Nación Argentina (1856-1865)”, en Garavaglia, Juan Carlos; 
Pro Ruíz, Juan y Zimmermann, Eduardo, Las fuerzas de guerra en la construcción del Estado. América Latina, Siglo XIX, Rosario: Prohistoria, pp. 413-456.

Garavaglia, Juan Carlos (2016). "Las fuerzas de guerra argentinas durante el conflicto de la Triple Alianza, 1865-1871", en Garavaglia, Juan C. y Fradkin, Raúl O. (Comps.) A 150 años de la Triple Alianza contra el Paraguay, Buenos Aires: Prometeo, pp. 107-132.

Goldman, Noemí y Salvatore, Ricardo (1998). Caudillismos rioplatenses. Nuevas miradas a un viejo problema, Buenos Aires: Eudeba.

Groussac, Paul (1939), Los que pasaban, Buenos Aires: Sudamericana.

Gutiérrez, Eduardo (1960) [1886]. Croquis y siluetas militares, Selección, Buenos Aires: Eudeba.

Halperín Donghi, Tulio (1982). Proyecto y construcción de una nación, Buenos Aires: Centro Editor de América Latina.

Macías, Flavia (2016). “El deber de enrolarse y el derecho a votar. Reflexiones en torno a la ciudadanía armada y el sufragio en argentina, 1863-1877", en Revista de Indias, Vol. LXXVI, núm. 266, pp. 233-258.

Macías, Flavia (2018). “Orden y violencia política. Argentina, 1870-1880", en Pasado Abierto, núm. 7, pp. 227-240.

Míguez, Eduardo (2003). “Guerra y Orden Social en los orígenes de la nación argentina, 1810-1880", en Anuario IEHS, n 18, pp. 17-38.

Míguez, Eduardo (2010). “La frontera sur de Buenos Aires y la consolidación del Estado liberal, 1852-1880”, en Bragoni y Míguez (2010).

Míguez, Eduardo (2011). Mitre Montonero, La revolución de 1874 y las formas de la política en la organización nacional, Buenos Aires: Sudamericana.

Oszlak, Oscar (1982). La formación del Estado argentino, Buenos Aires: Editorial de Belgrano.

Paz, Gustavo (2009). “El Roquismo en Jujuy: notas sobre élite y política, 18801910", en Anuario IEHS, n²4, pp. 389-410.

Paz, Gustavo (2010). "Resistencias populares a la expansión y consolidación del Estado nacional en el interior: La Rioja (1862-1863) y Jujuy (1874-1875)", en Oscar Moreno (Coord.) La construcción de la Nación Argentina, El rol de las fuerzas armadas. Buenos Aires: Ministerio de Defensa, Presidencia de la Nación.

Prado, Manuel (1942). Guerra al Malón, Buenos Aires: Editorial Americana.

Rodríguez, Augusto (1964). Reseña Histórica y Orgánica del Ejército Argentino, Buenos Aires: Dirección de Estudios Históricos, Secretaría de Guerra.

Sabato, Hilda (2009). “Resistir la imposición: revolución, ciudadanía y república en la Argentina de 1880", en Revista de Indias, vol. LXIX, n² 246, pp. 159-182. 
Saldías, Adolfo (1988) [1910]. Buenos Aires en el Centenario, Buenos Aires, Hyspamérica, Tomo III.

Serrano, Mario (1995). La capitalización de Buenos Aires y la revolución de Carlos Tejedor, Buenos Aires: Círculo Militar.

Tilly, Charles (1993). Coerción, capital y los Estados europeos 990-1990, Buenos Aires: Alianza Editorial.

Yangilevich, Melina (2006). “José Benito Machado. Construir poder en la frontera", en Raúl Mandrini (editor) Vivir entre dos mundos. Las fronteras del sur de la Argentina. Siglos XVIII y XIX, Buenos Aires: Taurus. 